\title{
TRADITION IN CONDITIONS OF MILITARY EXTREMENESS: FOLK WAYS OF UNDERSTANDING AND "OVERCOMING" THE GREAT PATRIOTIC WAR ${ }^{1}$
}

\author{
Marina A. Ryblova \\ Federal Research Center Southern Scientific Center of the Russian Academy of Sciences, \\ Rostov-on-Don, Russian Federation; \\ Volgograd State Institute of Arts and Culture, Volgograd, Russian Federation
}

\author{
Ekaterina V. Arkhipova \\ Volgograd State University, Volgograd, Russian Federation
}

\begin{abstract}
Introduction. In the study the authors consider the ways of understanding and overcoming the extreme conditions of the Great Patriotic The task is to define the forms and ways of "overcoming" the war conditions and its traumatizing consequences developed by Russians and to identify their connection with traditional types of worldview and folk ritual practices. Methods and materials. The analysis of folk stories recorded among different generations and rural Russian areas as well as memories about the wartime and the period after the Great Patriotic War compose the base of the article. According to the main task the authors use the method widely used in the Russian Ethnography which is called the "inside the tradition" view, or analysis from the position of its bearers. Analysis. The natural alternation of periods of prosperity and crises explains the inevitability of war, but according to popular beliefs, the impoverishment of the sacred sphere of life is the main factor of a tragedy. On the contrary, human turning to God and his / her repentance determine the possibility of overcoming a tragedy. The concept of "a rule" (and its violation) as well as the concept of "a destiny" (a shared fate) which must be restored and redistributed under the crisis according to popular beliefs play an important role in the mechanism of developing ways to "overcome" the war among the Russians during the wartime. Wartime ritual practices including baking and cutting bread, redistributing it to the front line, organizing joint meals, etc. confirm the statement. The process of the revival of religious (Orthodox) practices, and the formation of a collective memory of the war and the fallen heroes was inspired from below, from the masses. This initiative included folk forms of veneration and remembrance of the dead, the creation of sacred places associated with the war and the memory about it. Women, who became the main keepers of the tradition, who took upon themselves the functions of harmonizing the socio-psychological situation in rural areas during the difficult war and postwar years, were especially active in these processes. Results. The authors confirm the particular role of traditional types of worldview influencing the modern collective memory as well as social practices during both extreme conditions and everyday life. Ordinary people preferred to turn to centuries-old spiritual traditions of overcoming $\overrightarrow{\widetilde{\sigma}}$ war traumas and to use the experience of preserving collective memory of them formed in the pre-revolutionary ते time within the peasant and Cossack communities.

Key words: tradition, collective memory of the war, folk, ways of "overcoming" the war, understanding the If war, Great Patriotic War.

Citation. Ryblova M.A., Arkhipova E.V. Tradition in Conditions of Military Extremeness: Folk Ways of Understanding and "Overcoming” the Great Patriotic War. Vestnik Volgogradskogo gosudarstvennogo universiteta. Seriya 4. Istoriya. Regionovedenie. Mezhdunarodnye otnosheniya [Science Journal of Volgograd State University. History. Area Studies. International Relations], 2021, vol. 26, no. 1, pp. 216-228. (in Russian). DOI: https://doi.org/ 10.15688/jvolsu4.2021.1.19
\end{abstract}




\title{
ТРАДИЦИЯ В УСЛОВИЯХ ВОЕННОЙ ЭКСТРЕМАЛЬНОСТИ: НАРОДНЫЕ СПОСОБЫ ОСМЫСЛЕНИЯ И «ПРЕОДОЛЕНИЯ» ВЕЛИКОЙ ОТЕЧЕСТВЕННОЙ ВОЙНЫ ${ }^{1}$
}

\author{
Марина Александровна Рыблова \\ Федеральный исследовательский центр Южный научный центр РАН, \\ г. Ростов-на-Дону, Российская Федерация; \\ Волгоградский государственный институт искусств и культуры, г. Волгоград, Российская Федерация
}

\section{Екатерина Владимировна Архипова}

Волгоградский государственный университет, г. Волгоград, Российская Федерация

Аннотация. В статье на основе анализа народных рассказов, записанных в разное время в сельской местности России, выявляются формы и способы «преодоления» войны и ее травмирующих последствий, выработанные русским населением страны в годы Великой Отечественной войны и связанные как с мировоззренческими установками, так и с народными обрядовыми практиками. Исследование показало, что в экстремальных условиях Великой Отечественной войны русское население страны широко использовало веками наработанные духовные традиции преодоления кризисных ситуаций и опыт сохранения коллективной памяти о них, сформировавшиеся в дореволюционное время в рамках крестьянских и казачьих общин. Согласно народным представлениям, не только естественным чередованием периодов благополучия и кризисов объясняется неизбежность войны, но также оскудением сакральной сферы жизни, возможность же преодоления беды обусловливается обращением к Богу и покаянием. В механизме выработки способов «преодоления» войны в среде русского населения страны в военное время важнейшую роль играло понятие нормы (и ее нарушения), а также концепт «доли» (общей доли-судьбы), которая, по народным представлениям, в кризисной ситуации должна подвергаться обновлению и новому переделу. С этими представлениями связаны и обрядовые практики военного времени (выпечка и раздел хлебов, передача их по цепочке до линии фронта, организация совместных трапез и пр.). И в процессе возрождения религиозных (православных) практик, и в формировании коллективной памяти о войне первоначальная инициатива шла снизу, от народных масс и выражалась именно в народных формах почитания и поминовения умерших, в создании сакральных мест, связанных с войной и памятью о ней. Особую активность в этих процессах играли женщины, ставшие главными хранителями традиции, взявшими на себя функции гармонизации социально-психологической обстановки в сельской местности в тяжелые военные и послевоенные годы.

Ключевые слова: традиция, коллективная память о войне, народ, способы «преодоления» войны, осмысление войны, Великая Отечественная война.

Цитирование. Рыблова М. А., Архипова Е. В. Традиция в условиях военной экстремальности: народные способы осмысления и «преодоления» Великой Отечественной войны // Вестник Волгоградского государственного университета. Серия 4, История. Регионоведение. Международные отношения. - 2021. - Т. 26, № 1. - C. 216-228. - DOI: https://doi.org/10.15688/jvolsu4.2021.1.19

Введение. Исследователи особенностей функционирования и конструирования коллективной памяти уже неоднократно отмечали, что в современной культуре отчетливо просматриваются тенденции к возрождению и актуализации наследия традиционных сообществ, их ценностей и культурных программ. Традиционные типы мировоззрения оказывают существенное влияние как на современные нарративы коллективной памяти, так и на социальные практики, причем это происходит и в экстремальных условиях, и в повседневных ситуациях [13, с. 115]. Обращение к опыту архаики миллионов людей особенно наглядно было проявлено в годы Великой Отечественной войны и также уже стало предметом специального исследования [11, с. 106145; 27]. Однако основное внимание до сих пор уделялось материальным практикам, что касается духовной составляющей этой пробле- 
мы, то она нуждается в дальнейшей разработке. В связи с этим была сформулирована исследовательская задача: выявить формы и способы «преодоления» войны и ее травмирующих последствий, выработанные русским населением страны в годы Великой Отечественной войны и в первое послевоенное десятилетие и связанные как с мировоззренческими установками, так и с народными обрядовыми практиками.

Актуальность этого исследования обусловлена как недостаточной степенью ее изученности (в отечественной историографии анализ народного опыта переживания и «преодоления» войны и ее последствий еще значительно уступает в количественном отношении анализу деятельности в этой сфере официальных, в том числе религиозных, структур), так и сохраняющейся в современных реалиях тенденции к архаизации мировоззренческих установок и социальных практик, к использованию традиционных механизмов формирования и функционирования исторической коллективной памяти россиян в кризисных ситуациях жизни страны.

Методы и материалы. Сформулированная нами задача обусловила и выбор метода исследования, и набор источников. Поскольку нас в первую очередь интересовали традиционные способы преодоления войны и ее последствий, мы обратились к анализу источников, исходящих от самих носителей традиции, и сосредоточились на выявлении народного понимания причин бедствий и способов их преодоления. Такой методологический прием связан с широко применяемым в отечественной этнографии подходом, который называют взглядом «изнутри традиции», или анализом с позиции ее носителей. Так, в основу анализа были положены полевые записи, сделанные в разное время в сельской местности разных регионов России в ходе фольклорных и этнографических экспедиций. Они представляют собой воспоминания русского населения страны о Великой Отечественной войне и первых послевоенных годах и отражают именно народные мировоззренческие установки и социальные практики. Также широко использовались материалы исследований, проводившихся нами в 2014-2015 гг. в рамках целевого гранта РГНФ («Дети и война: культура повседневности, механизмы адаптации, стратегии и практики выживания в условиях Великой Отечественной войны»), в ходе которого было осуществлено 264 глубинных интервью, опубликованных в двух томах $[9 ; 10]$.

Анализ. Войны и другие бедствия в структуре народной памяти. В народном механизме преодоления войн и других бедствий важную роль играли традиционное восприятие времени и особенности коллективной памяти о минувших событиях. В их основе лежали представления о цикличности времени и постоянном чередовании периодов благоденствия и бедствий (кризисов), при этом последние понимались как неизбежное отклонение от когда-то (согласно народной мифологии - в момент Творения мира) заданной нормы. Постепенное старение мира воспроизводилось в цикличных народных календарных праздниках и представлялось как нарушение нормы и разрушение первичных границ. Главный смысл народных обрядов заключался в преодолении кризисной ситуации путем восстановления первоначальной нормы [3]. В такой картине мира регулярно происходившие в человеческой истории войны, голодоморы, эпидемии и другие кризисные ситуации представлялись как неизбежное и естественное развитие жизни, а не как случайное стечение обстоятельств. Нарушение же нормы в русской народной традиции соотносилось с представлениями о доле (коллективной и индивидуальной), понимаемой и как жизненная сила, и как доля-судьба [2]. В обрядах, направленных на преодоление кризисной ситуации, воспроизводилась процедура обновления не только старого мира, но и той доли, которая выделялась миру высшими силами.

О сохранении такого механизма народной памяти в среде русского населения страны в предвоенное время позволяют судить многочисленные записи устных рассказов, объединенных общей темой «знамения войн». В русской народной традиции о грядущих войнах и других бедствиях свидетельствуют самые различные знаки. Они являются как на небе (огненные столбы, кресты и пр.), так и на земле; бывают связаны с природой, миром людей и сакральными сферами. Весьма показательно, что образы-знамения Великой Отечественной войны в этих рассказах неред- 
ко соотносятся с теми, что были явлены и перед другими войнами: «Вот и перед ерманской так... Сначала кресты, а потом война» [5]. Нередко в рассказах встречаются мотивы противостоянии, сражения (всадников, столбов, птиц и пр.): «Соседка прибегает к нам: "Подите гляньте!”. Мы вышли на баз - на север столбы выходили. Красные, несколько столбов огненные. И вот они вот так сойдутся и потом расходятся. Перед войной это было. И в первый год войныl» [21]. Иногда столбы в рассказах имели вид радуги [18; 22]. В одном из устных рассказов речь идет о сне, в котором представлены две стрелы, сталкивающиеся на небе близ Уральских гор. А.Ф. Балашова сопоставила эти стрелы с армиями, сравнив их с обозначениями стрелками на карте передвижения армий [5]. Интересен в связи с этим рассказ, записанный в Могилевской области, в котором речь идет о перемещении с земли на небо человеческого воинства. Там накануне войны подростки видели при заходе солнца «как бы поднимающиеся от земли образы солдат с ружьями за плечами, которые уходили на небо» [31, с. 141].

Довольно часто в рассказах о знамениях войны, явленных на небе, встречаются образы животных: кони, птицы. Большинство из них связаны с традиционной символикой, так, кони, петухи и ястребы - с мужскими и юношескими возрастными группами. Однако предвоенное поколение нередко трактовало небесные знамения в духе советских реалий, определяя «красные» и «белые» образы в качестве символа «своих», а черные - в качестве вражеских: «Я в Калмыкии работала, меня война застала. Там легенда такая была. Два петуха встретились на небе. Один - красный, другой - черный. Дрались они, и вот красньй победил черного. И все говорили, когда началась война, мы победим все равно» [19]. Вместе с тем устойчиво сохраняются в народной памяти и представления о весьма архаичной цветовой триаде, в которой черный цвет противостоит белому как ритуально чистому и ассоциируется с нарушением традиции, грехом; белый соотносится с чистотой и бестелесностью иномирья; а красный связан с мотивом избыточности жизненной силы, энергии.
В рассказах о знамениях войны часто встречаются указания на отклонения от нормы, происходившие в земной сфере и связанные с понятиями чрезмерности, избытка. Так, повсеместно в России записывались рассказы о том, что накануне войн наблюдался необыкновенный урожай хлебов, грибов, ягод; с чрезмерностью плодились животные [5]. Нарушение нормы в сторону изобилия могло происходить и в мире людей. Так, по народным представлениям, свидетельствовать о грядущей войне могло рождение больше обычного мальчиков. Приметами войны могло стать и отклоняющееся от нормы поведение людей: слишком много плясали, с озлоблением дрались на кулачных боях [20].

Примерами очевидного нарушения границ между мирами (земным и небесным) могут также служить ситуации, когда людям являлись некие персонажи (обычно женщина или волк) и просили у них ткань [6, с. 205-206; 17]. На их потустороннее происхождение указывает ряд признаков: являются путнику голыми (без одежды/без шерсти), волк наделен даром речи, и женщина и волк, получив желаемое, пророчествуют. Нередко в рассказах женщина на дороге определяется как Божья Мать; она предсказывает скорую войну. Иногда, как знак грядущей войны трактовался сам факт ее объявления перед людьми в обнаженном виде или плачущей: «Он был шофером. И вот его послали в Нижний Дон. Он поехал. Едет, за Урюпино уже выехал, и вот тебе идет женщина вся наголо, Божья матерь. Машина встала. Он говорит: "Я не останавливал, ничего, а машина встала...”. Ждали после этого войну» [21].

Иногда в устных рассказах нагота женщины, встретившейся на дороге шоферу, прямо объясняется отлучением людей от Бога и их служением «другим» силам. Так, в рассказе, записанном в Брянской области, шофер встретил на мосту женщину, которая сама разъяснила причину своей наготы: «Вбегает женшина, совершенно наголо, останавливает машину и подает ему ведро крови и кусок сырого мяса. Шофер спрашивает: - Что это значит, почему ты голая? Она отвечает: - На кого ты сейчас служишь, отнял у нас все. - А ведро крови, это что значит? - $A$ вот кому ты сейчас 
служишь, так льется сейчас кровь через него» [6, с. 206].

Явления плачущей Богородицы фиксировались в разных регионах страны также в период борьбы с религией и массового разрушения церквей. Так, в одной из кубанских станиц в разоренном храме, по словам очевидцев, слышался рыдающий голос, который восклицал: «Боже мой, Боже мой, что вы наделали!». Жители станицы были уверены, «что это было видением Божьей матери» [12, с. 374 375]. Как предзнаменование великих бедствий трактовались в народе и случаи мироточения икон, массово происходившие в разных регионах страны накануне Великой Отечественной войны: «...в 1940-е годы почти в каждой деревне мироточили иконы, предвосхищая огромное количество невинных человеческих жертв» [16].

Обрядовые практики преодоления войны. Для преодоления кризисных ситуаций в дореволюционной России широко использовались практики сооружения в один день (oбblденкой) храмов, выпечки хлеба или изготовления полотна, которое называлось обыденнылм. По мнению Т.А. Бернштам, обычай изготовления в один день ткани-новины воссоздавал первичный миф - праформу творения, а значение слова «новина» восходит к мифологическому представлению о сотворении нового - молодого - взамен старого, как попытка дать новую жизнь явлению отмирающему или зараженному недугом, опасностью [7, с. 163]. В самые ответственные моменты земледельческого календаря в русских деревнях устраивались также коллективные пиры (братчины, ссыпки), на которых в складчину и общими усилиями готовили какое-то блюдо, символизировавшее общую долю, например, варили мед (медовуху), или выпекали многопудовые хлеба. Их совместное изготовление и употребление в пищу также символизировало обновление общей доли и новое ее перераспределение. Элементы этих древних обрядовых практик воспроизводились и в годы Великой Отечественной войны. Один из рассказов о такой практике записан нами в Волгограде: «Помню, как бабушка доила корову и раздавала молоко всем в деревне, по всей деревне, по баночкам. Помню, на столе у нас стояли баночки - много-много, кастрюльки, в общем, все приносили, и бабушка разливала и раздавала соседям это молоко. Не хватало ведь ничего, хлеба не было вообще... собирались все у иеркви, все люди, кто имел хоть немножечко продовольствия, все всё неслик этой ичеркви или относили прямо в саму цеерковь и в церкви еще раздавали еду. ...Взаимопомощь была необыкновенная. Как родственники все стали...» [9, с. 475].

В некоторых материалах представлены и более развернутые обрядовые действия, направленные на «преодоление» войны путем выпечки и раздачи хлебов [6, с. 207-209]. Так, согласно полевым записям, в 1943 г. в Брянской, Калужской и Смоленской областях получил распространение обычай печь хлеб всем селом и передавать его в соседнюю деревню, где он делился на кусочки и раздавался желающим. На одном из таких кусков замешивался и выпекался новый хлеб, который в свою очередь передавался дальше, в другую деревню. Ржаная мука для первых трех хлебов собиралась понемногу со всех дворов, процессу выпечки предшествовало общее моление, совершаемое «посеред деревни», а пекли хлеба на следующий день вдовы или девушки, обладающие, по народным представлениям, качествами ритуальной чистоты. Участники обряда были уверены, что когда хлеб достигнет линии фронта, немцы будут разбиты, и «война закончится: оттого, что много Богу молились» [6, с. 207]. В этом обряде также очевидна символика коллективного обновления доли и передачи ее советским воинам для обеспечения победы - как обновлялась и сила-энергия связанного семантически с воинством волка за счет передачи ему красной ткани. В селах Калужской области влияние православной традиции на обрядовые действия с хлебом выражалось в том, что по деревням молодые девушки носили «святой хлеб», представлявший собой пасхальные куличи, о которых говорили: «...пасхальный, якобы святой хлеб от Пасхи, посвященный якобы каким-то патриархам или попам...». Его также нужно было донести до линии фронта, чтобы обеспечить победу советским войскам [25, с. 24]. Опубликовавшая и прокомментировавшая часть этих материалов О. Белова отмечала, что в традиционном 
крестьянском быту подобное разделение хлеба или закваски с последующим их распространением по соседним деревням считалось действенным способом противостояния любым стихийным бедствиям, эпидемиям, мору скота [6, с. 207]. Таким образом, речь должна идти об использовании для «преодоления» войны русским сельским населением страны хорошо известных (традиционных) обрядовых практик, широко применявшихся и в других кризисных ситуациях.

Иногда в народных рассказах речь идет о таких обрядах, реальность осуществления которых легче опровергнуть, чем подтвердить, однако они также укладываются в вышеприведенные модели народного мировоззрения и практик «преодоления» войны. К числу таких рассказов можно отнести свидетельства о том, что во время войны представители военной и политической элиты страны обходили (или облетали на самолете) с иконами советские фронты и осажденные города. Так, фольклористы приводят рассказы о том, как Сталин ходил по фронтам с иконой в руках [30, c. 8]. Согласно народным преданиям, Ленинград также облетали с иконой на самолете во время блокады $[30$, с. 8$]$. В народной памяти до настоящего времени устойчиво сохраняются предания о «воздушных крестных ходах» над Сталинградом и Москвой. В последнем случае речь идет о легенде, согласно которой в конце 1941 г. в разгар битвы за Москву по приказу Сталина город облетел самолет с иконой Богородицы, что способствовало успеху советских войск. Затем облет с иконой Казанской Божьей Матери был совершен вокруг сражающегося Сталинграда. В вариантах последней легенды речь идет о том, что икона эта находилась затем на правом берегу Волги посреди советских войск, «шла» с войсками до границ СССР.

Эти рассказы также уходят корнями в древние обрядовые практики русских крестьян и казаков. Повсеместно в дореволюционной России в кризисные ситуации совершали обходы поселений и полей с иконами для обеспечения хорошего урожая и благополучия людей. При этом наиболее действенными считались такие, в которых принимали участие высокие церковные чины (архиереи). Процесс передачи «святости» иконы от поселения к поселению воспроизводится, например, в описании обряда, родившегося в хуторе Арпачинском (Область войска Донского) в год «губительной моровой язвы» и исполнявшегося впоследствии ежегодно: «...в хуторе Apnaчинском издавна совершается крестный ход 9 августа в Старочеркасскую станииу и обратно. Из Старочеркасской станиизы с крестным ходом приносится в хутор чудотворная икона Аксайской Божией Матери, и, при совершении пред ней молебного пения с акафистом во святом храме, притч обходит с этой святой иконой дома прихожан. Обхождение совершается в течение трех дней, именно с 9 по 12 августа, а затем в хутор Арпачинский является крестный ход из станицы Манычской, с которым святая икона переносится в сказанную станииу» [32, с. 183].

Что касается военного времени, то исследователи уже анализировали происходивший в годы Великой Отечественной войны взрыв религиозности среди населения страны и отмечали, что этот процесс шел снизу, инициатива исходила от народных масс, а официальные структуры в большинстве случаев вынуждены были лишь удовлетворять народный запрос. Так, в неурожайный 1946 г. сами крестьяне возродили традицию крестных ходов и молебнов на полях о даровании дождя; во время войны осуществляли в своих домах обряды крещения (погружения), отпевания, собирались в жилых домах для молений и пр. [26, с. 124]. Все послевоенное время во многих поселениях страны сохранялась традиция престольных (храмовых) праздников, которые проходили в том числе и в тех местах, где уже не было ни церквей, ни священнослужителей [1].

«Свои» могилки и народная память о погибших. Исследователи проблем коллективной памяти россиян о войне уже отмечали, что она имела два пласта, два уровня: собственно народный, связанный с «живой» и постоянно воспроизводимой коллективной памятью, и официальный, исходивший от государственных и партийных структур [28, с. 125]. Последний формировался в виде постоянного реконструирования и символизации памяти о Великой Отечественной войне, воплощавшихся в создании пантеонов героев, мемориалов, 
установке памятников, в разработке ритуалов официального празднования дня Победы и пр. Что касается собственно народной памяти о войне, то она опередила по времени официальные инициативы и отличалась от них по формам и содержанию. Т. Тимофеева рассмотрела различия этих двух пластов исторической памяти на примере памятников, устанавливаемых в честь погибших на войне или непосредственно на могилах. Она обратила внимание на то, что именно в сельской местности стали первоначально возникать простые и дешевые бетонные стелы-кенотафы со списками имен павших земляков, которые в большинстве случаев строились на средства местных жителей [28, с. 128]. Именно к этим памятникам стали приходить односельчане не только в День Победы, но и в поминальные дни христианского календаря. В первые послевоенные годы, когда День Победы еще не был официально утвержденным праздником, именно в кругу ближайших родственников и односельчан происходили поминовения павших воинов, нередко - в соответствии с христианскими и народными традициями.

В тех случаях, когда не было возможности прийти на могилу погибших родственников в силу отсутствия информации о месте их захоронения, возникали традиции создания мест коллективной памяти и почитания павших, вполне укладывающиеся в систему народного культа предков. Так, в военном Сталинграде местом почитания павших на фронтах и погибших в самом городе стала река Волга: «Папе в Волгу бросали иветь - так его и поминали» [10, с. 196]. Сталинград стал местом погребения его мирных жителей и солдат, не получивших, однако, отдельных могил и памятных знаков. В городе не возникло кладбища военного времени, так как мертвых закапывали в бомбовые воронки, хоронили во дворах и на улицах, стертых впоследствии масштабной перепланировкой. Однако потребность горожан в «родных могилках» была огромной, и еще до того как местом коллективных поминовений станет Мамаев курган, жители создавали свои собственные места памяти и скорби. Одним из таких мест стал Парк вдов, первое дерево в котором было посажено в 1965 г. работницей Волгоградского Тракторного завода в честь мужа, погибшего при обороне Сталинграда. Вслед за ней сотни женщин города высаживали здесь деревья в память о погибших мужьях и детях [14]. Традиция посадки деревьев в память умерших или по обету была широко распространена на Юге России, где в дореволюционное время повсеместно почитались «священные деревья». Так, жители хутора Рыбинский (Серафимовичский р-н Волгоградской обл.) рассказывали нам историю дерева, растущего на вершине Рыбинской горы: «Жил тут Василий Иванович. Во время войны попал в немеикий плен и обрёкся: если спасется, то посадит на Рыбинской горе дерево» [23].

Возникали народные места памяти и на самом Мамаевом кургане, ставшем главным символов Победы в городе и стране. Однако, не довольствуясь только официальными церемониями, многие ветераны войны, участники Сталинградской битвы на одном из склонов устроили собственное место памяти, куда приходили каждый год 9 мая: «Как раз на этом склоне Мамаева кургана, если мысленно провести ось от Родинь-матери к проспекту Ленина к углу завода ТДН, еще в 1980-х годах было несколько захоронений с простейшими деревянными обелисками, там всегда на 9 мая собирались участники Сталинградской битвы, поминали» [8].

Известны также случаи, когда женщины брали под особую опеку могилы неизвестных им людей, когда могил их близких не сохранилось: «...тетя моя, когда вернулась $c$ эвакуачии, она нашла труп советского солдата, рассказывала, при нем был медальон, она его сдала в военкомат, но так никто и не нашелся из родственников... И она его на своем огороде похоронила, недалеко от колодиа. Могилка всегда у него вся в иветах была, она засаживала ее многолетними цветами, такие они громофончиками были... И всегда могилка была ухоженная, и всегда она его поминала на День Победbl» [24]. Подобные случаи не были редкими, фиксировались исследователями и в других регионах страны. Иногда такие могилы становились со временем местами особого почитания и паломничества. Так, в деревне Латыши Калужской области фольклористы записали рассказ о могиле неизвестного лет- 
чика, ставшей со временем сакральным местом: «В 1950-е годы на нее натолкнулась Валентина Афанасьевна Михайлова и стала с тех пор ухаживать за могилкой, каждое лето навещзала ее. Шло время, и о могилке летчика стали слагаться таинственные и необъяснимые истории. И сама могила стала превращаться в некое мистическое и сакральное место. Сюда обязательно заходят случайные путники, грибники и ягодники, оставляют на могиле конфеты, печенье, ягоды и яблоки. Постепенно зародилось поверье, что летчик помогает, дает сильл» [25, с. 23].

Описанная выше сакрализация могилы неизвестного летчика на первый взгляд может быть трактована как простое почтение памяти героя войны, однако существенным здесь является указание на то, что в народе верили: «летчик помогает, дает силы». Это поверье уходит корнями в древние народные представления о том, что жизненная сила-доля человека, умершего «до срока» (прежде времени, насильственной смертью), остается до конца не истраченной, а потому может подлежать новому перераспределению среди живых посредством символического обмена (отсюда приношение на могилу конфет, печенья и пр.). Наиболее ярким обрядовым подтверждением этого может служить, например, повсеместно распространенная в России традиция установки голубияов (деревянных поминальных часовенок) на месте насильственной смерти какого-либо человека. Прохожие также оставляли на голубцах «поминные угощенья», полагая, что взамен получат силу и поддержку погибшего.

Сооружение голубцов на месте погребения воинов и использование их в культовых целях было известно во многих регионах дореволюционной России. Так, в начале $\mathrm{XX}$ в. Р.Л. Марков записал рассказ об обряде, совершаемом жителями села Красная Поляна Курской области на месте битвы между русскими и ногайцами, состоявшейся в 1709 году. По рассказам местных жителей, в войске ногайцев находился «престрашный великий богатырь», который был повержен в бою. Ему отсекли голову, и на этом месте выступили «капли целебной воды, темной, как кровь». Позднее здесь был сооружен голубец «о трех скатах, на трех развилочках». Голову богатыря многократно прокатали вокруг голубца, а затем уложили на его развилки. По словам Р.Л. Маркова, «это первое катание головы вокруг голубца легло в основу всех последующих обрядов»: такие «обкатывания» стали производиться здесь ежегодно и даже по несколько раз в год (от обряда до обряда голова лежала в развилках голубца) [15]. Очевидно, что голубец почитался курянами как место сохранения неистраченной жизненной силы ногайского богатыря: часть ее воплотилась в целебной воде, другая должна была переходить земле посредством ежегодных «обкатываний» для усиления ее плодородной силы. Отголоски этих представлений наглядно просматриваются и в почитании могилы неизвестного летчика из д. Латыши, и в сложившейся в послевоенное время традиции приходить на могилы неизвестных солдат, например, в дни бракосочетаний, которая в народной среде воспринималась и как отдание почести павшим, и как их особое «благословление» семейной паре.

В послевоенной российской деревне, потерявшей на войне огромное количество мужчин, главными хранителями памяти о них стали женщины-вдовы. О роли овдовевших женщин в гармонизации социально-психологической обстановки в сельской местности в тяжелые военные и послевоенные годы писала Л.А. Тульцева, отметившая, что они были представителями наиболее информированного в области ритуальных практик поколения. Исследовательница отмечала, что обычным явлением крестьянского общественного быта послевоенной деревни стали вдовы-чернички, которых в народе называли также «читалками» и «монашками», так как они организовывали религиозную жизнь жителей деревень: читали жития святых, молитвы, Псалтырь и другие богослужебные книги на общих собраниях верующих. В частых ситуациях отсутствия в деревнях и селах действующих церквей вдовы-чернички справляли на дому религиозные обряды и помогали своими знаниями и советом справить службу и поминки по убитым воинам в соответствии с религиозным каноном и местной традицией [29, с. 24].

Отметим, что и в дореволюционной России существовали сообщества вдов, которые 
брали на себя функции сохранения памяти об умерших или погибших мужьях и передачи ее молодому поколению. Нередко вдовы пытались взять на себя и обрядовые функции своих погибших мужей, исполняя «мужские» песни. Вместе с тем существовал и особый вдовский репертуар: набор песен с сюжетами о гибели на войне милого/мужа. Л.А. Тульцева указала на формирование особого женского (в том числе вдовского) фольклора в советское послевоенное время, включавшего в себя и частушки (с мотивами об убитом «дролечке» и женском «сиротстве»), и другие жанры [29, c. 21]. Многие советские вдовы прилагали огромные усилия для того, чтобы разыскать могилы погибших мужей и «навестить» их.

Именно в народной среде будет закладываться и традиция празднования Дня Победы. Основой этого народного праздника была поминальная трапеза, но обряд ею не ограничивался, давая возможность его участникам выхлестывать накопившиеся эмоции, причем именно в коллективных формах: «Сoбираются женщины... Выпьют, потом начинают плакать. Вот знаете, все плакали, буквально все женщины. Ну, кто вспоминает мужа, кто сына, кто брата. Но отмечали праздники таким образом. Потом выпили по второй. У кого что было, приносили на общий стол. Закусили, потом начинали песни петь. Вот тут уже начинался настоящий праздник, когда запевали. Но песни пели тоже все военных лет» [10, с. 264]. О массовых посещениях кладбищ на Пасху, Троицу и в так называемые «родительские поминные дни» рассказывали многие наши информанты-сталинградцы.

Результаты. Проведенное исследование показало, что в экстремальных условиях Великой Отечественной войны русское население страны широко использовало веками наработанные духовные традиции преодоления кризисных ситуаций и опыт сохранения коллективной памяти о них, сформировавшиеся в дореволюционное время в рамках крестьянских и казачьих общин. В сознании людей, переживших период борьбы с религией и массовое отлучение от церкви и веры, существовало собственное понимание причин грядущей войны. Согласно народным представлениям, не только естественным чередовани- ем периодов благополучия и кризисов объясняется неизбежность войны, но также оскудением сакральной сферы жизни, началом служения «иным силам»; возможность же преодоления беды обусловливается обращением к Богу и покаянием.

Анализ народных рассказов о знамениях/предсказаниях войны показал, что в осмыслении причин бедствий и способов их «преодоления〉 в среде русского населения страны в военное время важнейшую роль играло понятие нормы (и ее нарушения), а также концепт «доли» (общей доли-судьбы), которая, по народным представлениям, в кризисной ситуации должна подвергаться обновлению и новому переделу. С этими представлениями связаны и обрядовые практики военного времени, направленные на то, чтобы каждый участник обряда мог внести свою «долю» в общую долю-судьбу с последующей передачей ее на фронт советским солдатам (то есть с обновлением и новым перераспределением).

А.Ф. Балашова, исследовавшая народные рассказы о знамениях Великой Отечественной войны, отметила, что для этого жанра характерен коммуникативный посыл из прошлого в современность, от одного поколения к другому: «Сохраняется связь и взаимная переводимость мировоззрений старшего поколения с традиционным видением мира современного (подвергшегося влиянию газет, телевидения, Интернета, массовой культуры) человека, но интерпретирующего мир с помощью той же образной и понятной сетки» $[4$, c. 238]. Тем более можно говорить о степени воздействия мировоззрения старшего поколения на общие жизненные установки и поведенческие практики советского общества в предвоенное и военное время. Несмотря на влияние советской идеологии на трактовки образов знамений грядущей войны, в них устойчиво сохранялись элементы той самой «образной и понятной сетки» традиционного восприятия экстремальных ситуаций, осмысления их причин и способов преодоления.

О возрождении религиозности, о взаимоотношении церковных организаций и государственных органов в годы войны написано немало работ. Наше исследование показало, что инициативы в этой сфере шли снизу, от народных масс, и выражались именно в народных 
формах почитания и поминовения умерших, в создании сакральных мест, связанных с войной и памятью о ней.

\section{ПРИМЕЧАНИЕ}

${ }^{1}$ Публикация подготовлена в рамках реализации государственного задания ЮНЦ РАН, № гр. проекта АAАA-A20-120122990111-9.

The research was supported by the South Scientific Center of the Russian Academy of Science № AAAA-A20-120122990111-9.

\section{СПИСОК СОКРАЩЕНИЙ}

$$
\begin{aligned}
& \text { ПЗ - полевая запись. } \\
& \text { Г.p. - год рождения. } \\
& \text { Д. - деревня. } \\
& \text { Обл. - область. } \\
& \text { Р-н- район. } \\
& \text { С. - село. } \\
& \text { Сm-ца - станица. } \\
& \text { Хуm-хутор. }
\end{aligned}
$$

\section{СПИСОК ЛИТЕРАТУРЫ}

1. Амосов, Н. О вреде религиозных праздников / Н. Амосов // Колхозный активист. - 1954. № 68 (25 авг.).

2. Байбурин, А. К. Обрядовое перераспределение доли у русских / А. К. Байбурин // Судьба традиционной культуры. - СПб. : РАН : Рос. ин-т истории искусств, 1998. - С. 78-82.

3. Байбурин, А. К. Ритуал в традиционной культуре. Структурно-семантический анализ восточнославянских обрядов / А. К. Байбурин. - СПб. : Наука, 1993. - 237 с.

4. Балашова, А. Ф. Коммуникативная природа народных рассказов на примере текстов о Великой Отечественной войне в небесных знамениях / А. Ф. Балашова // Коммуникативные исследования. - 2014. - № 1. - С. 233-240.

5. Балашова, А. Ф. Природные и метеорологические приметы войны / А. Ф. Балашова // Фольклор и постфольклор : сайт. - Электрон. текстовые дан. - Режим доступа: https://ruthenia.ru/folklore/ folklorhttps://ruthenia.ru/folklore/folklorelaboratory/ Balashova.htmelaboratory/Balashova.htm (дата обращения: 01.09.2020). - Загл. с экрана.

6. Белова, О. Рассказы о знамениях войны из Брянской области: к вопросу о типологии сюжетов / О. Белова // Западный регион России в международных отношениях $\mathrm{X}-\mathrm{XX}$ вв. (Брянск, 28-30 нояб.
2013 г.) : материалы II Междунар. науч. конф. / ред. С. И. Михальченко, А. А. Чубур. - Брянск : Изд-во БГУ, 2013. - С. 203-211.

7. Бернштам, Т. А. Молодежь в обрядовой жизни русской общины XIX-XX вв. Половозрастной аспект традиционной культуры / Т. А. Бернштам. - Л. : Наука. Ленингр. отд-ние, 1988. - 277 с.

8. Был ли на Мамаевом кургане парк Сталинградских вдов // Город героев. - Электрон. текстовые дан. - Режим доступа: http://gg34.ru/surprised/ 26290-byl-li-v-volgograde-park-stalingradskikhvdov.html (дата обращения: 01.06.2020). - Загл. с экрана.

9. Дети и война: Сталинградская битва и жизнь в военном Сталинграде в воспоминаниях жителей города / под ред. М. А. Рыбловой. - Волгоград : Изд-во Волгогр. фил. РАНХиГС, 2014. - 512 с.

10. Дети Сталинграда: 10 лет после войны. Воспоминания жителей города / под ред. М. А. Рыбловой. - Волгоград : Изд-во Волгогр. фил. РАНХиГС, 2015. - $360 \mathrm{c}$.

11. Детство и война: культура повседневности, механизмы адаптации и практики выживания детей в условиях Великой Отечественной войны (на материалах Сталинградской битвы) / М. А. Рыблова, Е. Ф. Кринко, Т. П. Хлынина, Е. В. Архипова, И. И. Курилла, М. П. Назарова. - Волгоград : Изд-во Волгогр. фил. РАНХиГС, 2015. - 336 с.

12. Крестная ноша / сост. и коммент. В. Сидоров // Трагедия казачества : сборник / ред.-сост. Л. Барыкина. - М. : Молодая гвардия, 1994. - 606 с.

13. Кузмин, Н. Н. Особенности коллективной памяти в традиционных обществах / Н. Н. Кузмин // Ученые записки Крымского федерального университета им. В.И. Вернадского. Философия. Политология. Культурология. - 2017. - Т. 3 (69), № 2. С. 114-124.

14. Ланский, М. Вырубка парка вдов стала последней каплей / М. Ланский // Волга - Каспий. Электрон. текстовые дан. - Режим доступа: https:// volga-kaspiy.ru/society/vyrubka-parka-vdov-stalaposledney-kapley.html (дата обращения: 08.09.2020). Загл. с экрана.

15. Марков, Р. А. Голубец на Красной Поляне / Р. А. Марков // Труды Курской Губернской Архивной Комиссии. Вып. 1. - Курск : Типография Курского губернского земства, 1911. - С. 138-163.

16. Отец Михаил. Грандиозное мироточение в Твери - знамение Небесной Мирротвери // Сайт Общины Православной церкви Державная г. Твери. - Электрон. текстовые дан. - Режим доступа: http://mirotver.ru/features/90-grandioznoemirotochenie-v-tveri.htm (дата обращения: 08.10.2020). - Загл. с экрана.

17. Петров, Н. Как баба в белом войну предсказала: эсхатологические настроения в СССР 
/ Н. Петров // Мифологические модели и ритуальное поведение в советском и постсоветском пространстве / сост. А. Архипова. - М. : Изд-во РГГУ, 2013. - C. 188-199.

18. ПЗ 1997 г. в ст-це Тепикинской. Информант Е.Г. Великанова, 1930 г.р. Материалы этнографической практики студентов ВолГУ // Личный архив М.А. Рыбловой.

19. ПЗ 1997 г. в ст-це Тепикинской. Информант Е.Ф. Арбузова, 1920 г.р. Материалы этнографической практики студентов ВолГУ // Личный архив М.А. Рыбловой.

20. ПЗ 1997 г. в ст-це Тепикинской. Информант Р.Ф. Кривова, 1912 г.р. // Личный архив М.А. Рыбловой.

21. ПЗ 1997 г. в ст-це Тепикинской. Информант М.П. Усачева, 1921 г.р. Материалы этнографической практики студентов ВолГУ // Личный архив М.А. Рыбловой.

22. ПЗ 1997 г. в ст-це Тепикинской. Информант П.В. Кондрашова, 1929 г.р. Материалы этнографической практики студентов ВолГУ // Личный архив М.А. Рыбловой.

23. ПЗ автора в хут. Рыбинском Серафимовичского р-на Волгоградской обл. // Личный архив М.А. Рыбловой.

24. ПЗ М. Пономаревой 2013 , г. Волгоград. Информант А.В. Склярова, 1948 г.р., г. Сталинград // Личный архив М.А. Рыбловой.

25. Рассказы о войне в Калужской области / предисл. и публ. Л. Ф. Миронихиной // Живая старина. - 2010. - № 2. - С. 23-26.

26. Редькина, О. Ю. Народная религиозная культура в 1940-х гг.: на примере Сталинградской области / О. Ю. Редькина, С. В. Мордвинов // Вестник Волгоградского государственного университета. Серия 7, Философия. Социология и социальные технологии. - 2012. - № 1 (21). - С. 121-126.

27. Рыблова, М. А. Практики «преодоления войны» мирными жителями послевоенного Сталинграда / М. А. Рыблова // Татьяна Павловна Хлынина in memoriam. - Ростов н/Д : ЮНЦ РАН, 2017. C. 530-548.

28. Тимофеева, Т. Историческая память и ее памятники (на примере материалов Великой Отечественной войны) / Т. Тимофеева // Россияне и немцы в эпоху катастроф. - М. : РОССПЭН, 2012.C. $122-135$.

29. Тульцева, Л. А. Вдовья доля (заметки этнографа) / Л. А. Тульцева // Этнографическое обозрение. - 1995. - № 3. - С. 20-26.

30. Фольклор военных лет / публ. Е. А. Самоделовой // Живая старина. - 2005. - № 2. - С. 8-13.

31. Фурсова, Е. Ф. Чудесные видения/знамения накануне Великой Отечественной войны 19411945 гг. / Е. Ф. Фурсова // Вестник Томского госу- дарственного университета. История. - 2017. № 49. - C. 128-131.

32. Церковно-приходские летописи Донской и Новочеркасской епархии / сост., автор коммент. А. В. Шадрина. - Ростов н/Д : Донской издательский дом, 2019. - 304 с.

\section{REFERENCES}

1. Amosov N. O vrede religioznykh prazdnikov [On the Dangers of Religious Holidays]. Kolkhoznyy activist, 1954, no. 68, August 25.

2. Bayburin A.K. Obryadovoye pereraspredeleniye doli u russkikh [Ritual Redistribution of the Share of Russians]. Sud'ba traditsionnoy kul'tury [Fate of Traditional Culture]. Saint Petersburg, RAN. Rossiyskiy institut istorii iskusstv, 1998, pp. 78-82.

3. Bayburin A.K. Ritual v traditsionnoy kul'ture. Strukturno-semanticheskiy analiz vostochnoslavyanskikh obryadov [Ritual in Traditional Culture. Structural and Semantic Analysis of East Slavic Rituals]. Saint Petersburg, Nauka Publ., 1993. $237 \mathrm{p}$.

4. Balashova A.F. Kommunikativnaya priroda narodnykh rasskazov na primere tekstov o Velikoy Otechestvennoy voyne v nebesnykh znameniyakh [The Communicative Nature of Folk Stories on the Example of Texts About the Great Patriotic War in Heavenly Signs]. Kommunikativnyye issledovaniya, 2014, no. 1, pp. 233-240.

5. Balashova A.F. Prirodnye i meteorologicheskie primety vojny [Natural and Meteorological Signs of War]. Fol'klor i postfol'klor: sayt [Folklore and Postfolklor: Website]. URL: https://ruthenia.ru/ folklore/folklorhttps://ruthenia.ru/folklore/ folklorelaboratory/Balashova.htmelaboratory/ Balashova.htm (accessed 1 September 2020).

6. Belova O. Rasskazy o znamenijah vojny iz Brjanskoj oblasti: k voprosu o tipologii sjuzhetov [Stories About the Signs of War from the Bryansk Region: To the Question of the Typology of Stories]. Mihal'chenko S.I., Chubur A.A., eds. Zapadnyj region Rossii $v$ mezhdunarodnyh otnoshenijah $X-X X v v$. (Brjansk, 28-30 nojabrja 2013 g.): materialy II Mezhdunar. nauch. konf. [The Western Region of Russia in International Relations of the $10^{\text {th }}-$ $20^{\text {th }}$ Centuries (Bryansk, November 28-30, 2013). Proceedings of the II International Scientific Conference]. Bryansk, Izd-vo BGU, 2013, pp. 203-211.

7. Bernshtam T.A. Molodezh'v obrjadovoj zhizni russkoj obshhiny $X I X-X X$ vv. Polovozrastnoj aspekt tradicionnoj kul'tury [Youth in the Ritual Life of the Russian Community of the $19^{\text {th }}-20^{\text {th }}$ Centuries. Gender and Age Aspect of Traditional Culture]. Leningrad, Nauka. Leningradskoe otdelenie, 1988. 277 p. 
8. Byl li na Mamaevom kurgane park Stalingradskih vdov [Was there a Park of Stalingrad Widows on Mamayev Kurgan]. Gorod geroev [City of Heroes]. URL: http://gg34.ru/surprised/26290-bylli-v-volgograde-park-stalingradskikh-vdov.html (accessed 1 June 2020).

9. Ryblova M.A., ed. Deti $i$ vojna: Stalingradskaja bitva i zhizn'v voennom Stalingrade $v$ vospominanijah zhitelej goroda [Children and War: the Battle of Stalingrad and Life in Military Stalingrad in the Memories of City Residents]. Volgograd, Izd-vo Volgogradskogo filiala RANKhiGS, 2014. 512 p.

10. Ryblova M.A., ed. Deti Stalingrada: 10 let posle vojny. Vospominanija zhitelej goroda [Children of Stalingrad: 10 Years After the War. Memories of City Residents]. Volgograd, Izd-vo Volgogradskogo filiala RANKhiGS, 2015.360 p.

11. Ryblova M.A., Krinko E.F., Khlynina T.P., Arkhipova E.V., Kurilla I.I., Nazarova M.P. Detstvo $i$ vojna: kul tura povsednevnosti, mehanizmy adaptacii $i$ praktiki vyzhivanija detej $v$ uslovijah Velikoj Otechestvennoj vojny (na materialah Stalingradskoj bitvy) [Childhood and War: Culture of Everyday Life, Mechanisms of Adaptation and Survival Practices of Children in the Conditions of the Great Patriotic War (Based on the Materials of the Battle of Stalingrad)]. Volgograd, Izd-vo Volgogradskogo filiala RANKhiGS, 2015. 336 p.

12. Sidorov V., ed. Krestnaja nosha [God's Burden]. Tragedija kazachestva: sbornik [Tragedy of the Cossacks: Collection]. Moscow, Molodaya gvardiya Publ., 1994. 606 p.

13. Kuzmin N.N. Osobennosti kollektivnoj pamjati $\mathrm{v}$ tradicionnyh obshhestvah [Features of Collective Memory in Traditional Societies]. Uchenye zapiski Krymskogo federal'nogo universiteta im. V.I. Vernadskogo. Filosofija. Politologija. Kul'turologija, 2017, vol. 3 (69), no. 2, pp. 114-124.

14. Lanskij M. Vyrubka parka vdov stala poslednej kaplej [Cutting Down the Park of Widows Was the Last Straw]. Volga-Kaspij [Volga-Caspian]. URL: https:// volga-kaspiy.ru/society/vyrubka-parka-vdov-stalaposledney-kapley.html (accessed 8 October 2020).

15. Markov R.A. Golubec na Krasnoj Poljane [The Golubec in Krasnaya Polyana]. Trudy Kurskoj Gubernskoj Arhivnoj Komissii. Vyp. 1 [Proceedings of the Kursk Provincial Archival Commission. Iss. 1]. Kursk, Tipografiya Kurskogo gubernskogo zemstva, 1911, pp. 138-163.

16. O. Mihail. Grandioznoe mirotochenie v Tveri znamenie Nebesnoj Mirrotveri [A Grand Occurrence in Tver-A Sign of Heavenly Mirrolure]. Sayt Obshhiny Pravoslavnoj cerkvi Derzhavnaja g. Tveri [Website of the Community of the Orthodox Church Derzhavnaya in Tver]. URL: http://mirotver.ru/ features/90-grandioznoe-mirotochenie-v-tveri.htm (accessed 8 October 2020).
17. Petrov N. Kak baba $v$ belom vojnu predskazala: jeshatologicheskie nastroenija v SSSR [How the Woman in White Predicted the War: Eschatological Moods in the USSR]. Arkhipova A., ed. Mifologicheskie modeli i ritual'noe povedenie $v$ sovetskom $i$ postsovetskom prostranstve [Mythological Models and Ritual Behavior in the Soviet and Post-Soviet Space]. Moscow, Izd-vo RGGU, 2013,pp. 188-199.

18. PZ 1997 g. v st-tse Tepikinskoy. Informant E.G. Velikanova, 1930 g.r. Materialy etnograficheskoy praktiki studentov VolGU [Field Record of 1997 in Tepikinskaya Stanitsa. Informant E.G. Velikanova, Born in 1930. Materials of Ethnographic Practice of Volgograd State University Students]. Lichnyy arkhiv M.A. Ryblovoy [Personal Archive by M.A. Ryblova].

19. PZ 1997 g. v st-tse Tepikinskoy. Informant E.F. Arbuzova, 1920 g.r. Materialy etnograficheskoy praktiki studentov VolGU [Field Record of 1997 in Tepikinskaya Stanitsa. Informant E.F. Arbuzova, Born in 1920. Materials of Ethnographic Practice of Volgograd State University Students]. Lichnyy arkhiv M.A. Ryblovoy [Personal Archive by M.A. Ryblova].

20. PZ 1997 g. v st-tse Tepikinskoy. Informant R.F. Krivova, 1912 g.r. [Field Record of 1997 in Tepikinskaya Stanitsa. Informant R.F. Krivova, Born in 1912]. Lichnyy arkhiv M.A. Ryblovoy [Personal Archive by M.A. Ryblova].

21. PZ 1997 g. v st-tse Tepikinskoy. Informant M.P. Usacheva, 1921 g.r. Materialy etnograficheskoy praktiki studentov VolGU [Field Record of 1997 in Tepikinskaya Stanitsa. Informant M.P. Usacheva, Born in 1921. Materials of Ethnographic Practice of Volgograd State University Students]. Lichnyy arkhiv M.A. Ryblovoy [Personal Archive by M.A. Ryblova].

22. PZ 1997 g. v st-tse Tepikinskoy. Informant P.V. Kondrashova, 1929 g.r. Materialy etnograficheskoy praktiki studentov VolGU [Field Record of 1997 in Tepikinskaya Stanitsa. Informant P.V. Kondrashova, Born in 1929. Materials of Ethnographic Practice of Volgograd State University Students]. Lichnyy arkhiv M.A. Ryblovoy [Personal Archive by M.A. Ryblova].

23. PZ avtora vkhut. Rybinskom Serafimovichskogo r-na Volgogradskoy obl. [Field Record in Rybinsky Khutor in Serafimovich District of Volgograd Oblast]. Lichnyy arkhiv M.A. Ryblovoy [Personal Archive by M.A. Ryblova].

24. PZ M. Ponomarevoy 2013, g. Volgograd. Informant A.V. Sklyarova, 1948 g.r., g. Stalingrad [Field Record by M. Ponomareva, 2013, Volgograd. Informant A.V. Skljarova, Born in 1948, Stalingrad]. Lichnyy arkhiv M.A. Ryblovoy [Personal Archive by M.A. Ryblova].

25. Mironihina L.F., ed. Rasskazy o vojne v Kaluzhskoj oblasti [Stories About the War in the Kaluga Region]. Zhivaja starina, 2010, no. 2, pp. 23-26. 
26. Red'kina O.Yu., Mordvinov S.V. Narodnaya religioznaya kultura v 1940-kh gg.: na primere Stalingradskoy oblasti [National Religious Culture in the 1940s: The Stalingrad Oblast Case Study]. Vestnik Volgogradskogo gosudarstvennogo universiteta. Seriya 7. Filosofiya. Sotsiologiya i sotsialnyye tekhnologii [The Science Journal of Volgograd State University. Philosophy. Sociology and Social Technologies], 2012, no. 1 (21), pp. 121-126.

27. Ryblova M.A. Praktiki «preodolenija vojny» mirnymi zhiteljami poslevoennogo Stalingrada [Practices of "Overcoming the War" by Civilians of Post-War Stalingrad]. Tat'jana Pavlovna Hlynina in memoriam. Rostov-on-Don, YuNTz RAN, 2017, pp. 530-548.

28. Timofeeva T. Istoricheskaja pamjat' i ee pamjatniki (na primere materialov Velikoj Otechestvennoj vojny) [Historical Memory and Its Monuments (On the Example of Materials of the Great
Patriotic War)]. Rossijane i nemcy v jepohu katastrof [Russians and Germans in the Era of Catastrophes]. Moscow, ROSSPEN Publ., 2012, pp. 122-135.

29. Tul'ceva L.A. Vdov'ja dolja (zametki jetnografa) [Widow's Destiny (Ethnographer's Notes)]. Jetnograficheskoe obozrenie, 1995, no. 3, pp. 20-26.

30. Fol'klor voennyh let [Folklore of the War Years]. Zhivaja starina, 2005, no. 2, pp. 8-13.

31. Fursova E.F. Chudesnye videnija/znamenija nakanune Velikoj Otechestvennoj vojny 1941-1945 gg. [Wonderful Visions / Signs on the Eve of the Great Patriotic War of 1941-1945]. Vestnik Tomskogo gosudarstvennogo universiteta. Istorija, 2017, no. 49, pp. 128-131.

32. Shadrina A.V., ed. Cerkovno-prihodskie letopisi Donskoj i Novocherkasskoj eparhii [Parish Chronicles of the Don and Novocherkassk Diocese]. Rostov-on-Don, Donskoy izdatelskiy dom, 2019.304 p.

\section{Information About the Authors}

Marina A. Ryblova, Doctor of Sciences (History), Associate Professor, Leading Researcher, Kazachestvo Laboratory, Federal Research Center Southern Scientific Center of the Russian Academy of Sciences, Chekhova St, 41, 344006 Rostov-on-Don, Russian Federation; Professor, Department of Traditional Culture and Folk Instrumental Performance, Volgograd State Institute of Arts and Culture, Tsiolkovskogo St, 4, 400001 Volgograd, Russian Federation, ryblova@mail.ru, https://orcid.org/0000-0003-1451-2579

Ekaterina V. Arkhipova, Candidate of Sciences (History), Associate Professor, Department of International Relations, Political Science and Area Studies, Volgograd State University, Prosp. Universitetsky, 100, 400062 Volgograd, Russian Federation, arkhipovakv@volsu.ru, https://orcid.org/0000-0003-1891-5586

\section{Информация об авторах}

Марина Александровна Рыблова, доктор исторических наук, доцент, ведущий научный сотрудник Лаборатории казачества, Федеральный исследовательский центр Южный научный центр РАН, просп. Чехова, 41, 344006 г. Ростов-на-Дону, Российская Федерация; профессор кафедры традиционной культуры и народного инструментального исполнительства, Волгоградский государственный институт искусств и культуры, ул. Циолковского, 4, 400001 г. Волгоград, Российская Федерация, ryblova@mail.ru, https://orcid.org/0000-0003-1451-2579

Екатерина Владимировна Архипова, кандидат исторических наук, доцент кафедры международных отношений, политологии и регионоведения, Волгоградский государственный университет, просп. Университетский, 100, 400062 г. Волгоград, Российская Федерация, arkhipovakv@volsu.ru, https://orcid.org/0000-0003-1891-5586 